\title{
STUDY ON LAMINATED RUBBER BEARING BASE ISOLATORS FOR SEISMIC PROTECTION OF STRUCTURES
}

\author{
Ganga Warrier $\mathbf{A}^{1}$, Balamonica $\mathrm{K}^{2}$, Sathish Kumar $\mathrm{K}^{3}$, Dhanalakshmi ${ }^{4}$ \\ ${ }^{I}$ M.Tech Structural Engineering Student, Department of Civil Engineering, Manipal Institute of Technology, \\ Karnataka, India \\ ${ }^{2}$ Senior Project Fellow, CSIR-Structural Engineering Research Centre, Council of Scientific and Industrial Research, \\ Chennai, India \\ ${ }^{3}$ Senior Principal Scientist, CSIR-Structural Engineering Research Centre, Council of Scientific and Industrial \\ Research, Chennai, India \\ ${ }^{4}$ Assistant Professor, Department of Civil Engineering, Manipal Institute of Technology, Karnataka, India
}

\begin{abstract}
Base isolation or seismic base isolation is an effective means for protection of structures, its contents and its occupants during the event of an earthquake. The principle of base isolation is vibration isolation. It decouples the building from damaging action of the earthquake. The isolator partially reflects and partially absorbs input seismic energy before it gets transmitted to the superstructure. Laminated Rubber Bearing Isolators are placed between the superstructure and foundation, which reduces the horizontal stiffness of the system. It thereby increases the time period of the structure and decreases the spectral acceleration of the structure. The superstructure acts like a rigid body, thus inter storey drift is reduced. Such type of isolators are used in practice in India, yet a proper design procedure based on IS code is unavailable. The paper presents design procedure for LRB adopting the procedure of IS 1893:2002 (Part-1) for earthquake resistant design of buildings. Design charts have been developed and presented in this paper which gives isolator diameter and rubber thickness as design outputs. The design procedure requires different input parameters like fundamental period and damping of the fixed base structure, axial load on the column, seismic zone, type of soil and shore hardness of rubber. These design charts enable the designer to easily arrive at the isolator parameters to achieve seismic isolation. Using the charts, case study has been done using SAP2000. Building displacement and acceleration are compared for model with and without base isolator. Comparative study of linear and non-linear base isolators has also been carried out. Linear and non-linear time history analysis has been done using El Centro earthquake.
\end{abstract}

Keywords: base isolation, laminated rubber bearing, IS Code, seismic protection, design charts, time history analysis, SAP2000

\section{INTRODUCTION}

Earthquake is one of the major natural disasters which cause damages to the buildings. Due to its damaging power, it is not only important to have strong structures, but also seismically protected structures. Base isolation is a simple and practically feasible method of seismic protection of structures.

\subsection{Base Isolation}

There are two major types of base isolation, namely, elastomeric and sliding. Both systems are designed to take the weight of the building and let the foundations move sideways during an earthquake. This paper deals with the laminated rubber bearing isolator, which falls under the first category. A layer of rubber with much lower horizontal stiffness is introduced between superstructure and the foundation. After the isolation, the system has a natural period much longer than the fixed base natural period. A typical low damping natural rubber bearing isolator is shown in Figure 1[1].
When the period is increased, pseudo-acceleration is decreased and hence the force in the structure gets reduced (Figure 2[2]). However, the displacement of the system increases drastically. This is due to the deformation of the rubber layer.

LRB isolators have cylindrical rubber bearings, which are reinforced with steel shims. Shims and rubber is placed as alternate layers. Steel plates are also provided at the two ends of the isolator. The steel shims boost the load carrying capacity, thus the structure is stiff under vertical loads and flexible under horizontal loads. 


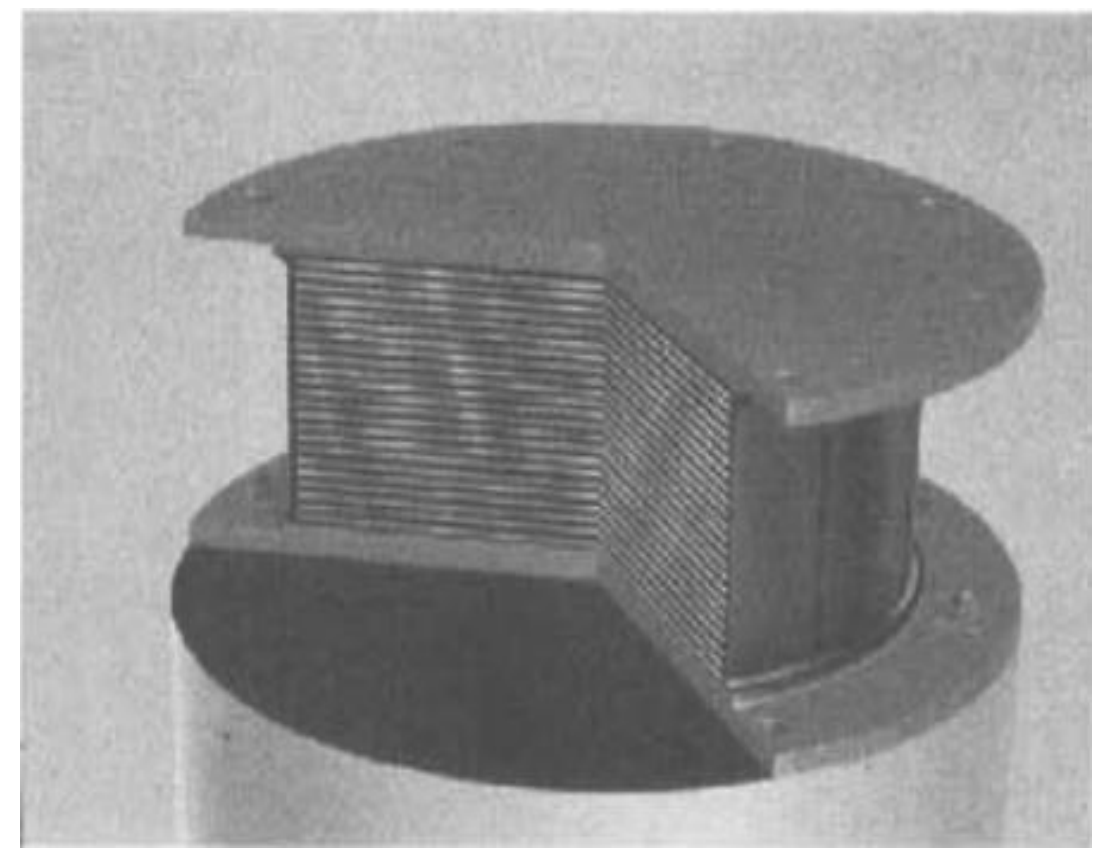

Fig -1: Low damping natural rubber bearing[1]

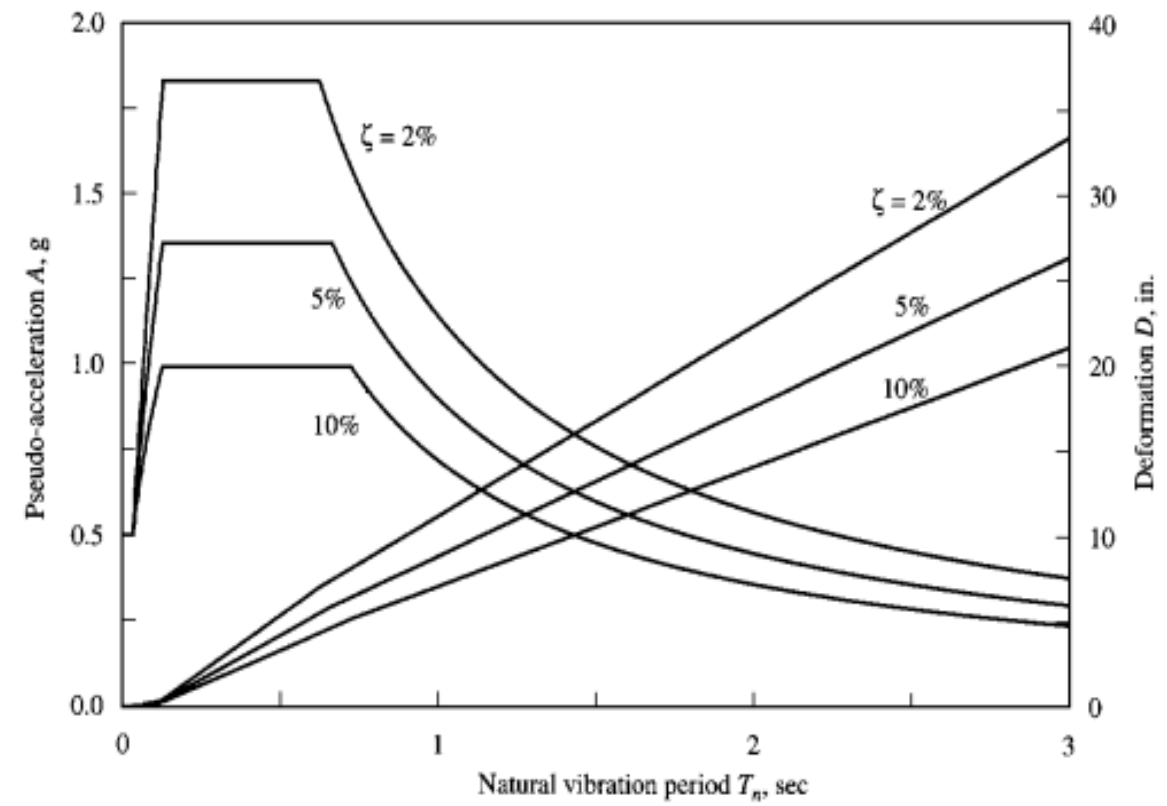

Fig -2: Elastic design spectrum [2]

\subsection{Linear Theory of Base Isolation}

This can be explained based on two-mass structural model as shown in Figure 3[1]. The mass $m$ represents the superstructure of the building and $m_{b}$ mass of the base floor above the isolation system. The other parameters are structural stiffness $\left(K_{s}\right)$ and damping $\left(C_{s}\right)$ and base isolator stiffness $\left(K_{b}\right)$ and damping $\left(C_{b}\right)$. The absolute displacements of the masses are given by $U_{s}$ and $U_{b}$ and the ground displacement is given by $U_{g}$. Therefore, the relative displacements are given by

$$
\mathrm{V}_{\mathrm{b}}=\mathrm{U}_{\mathrm{b}}-\mathrm{U}_{\mathrm{g}} \quad V_{s}=U_{s}-U_{g}
$$

The basic equations of motion of the two-degree-of-freedom system are

$\left(\mathrm{m}+\mathrm{m}_{\mathrm{b}}\right) \ddot{v}_{\mathrm{b}}+\mathrm{m}_{\mathrm{s}}+\mathrm{C}_{\mathrm{b}} \dot{v}_{\mathrm{b}}+\mathrm{K}_{\mathrm{b}} \mathrm{V}_{\mathrm{s}}=-\left(\mathrm{m}+\mathrm{m}_{\mathrm{b}}\right) \ddot{\mathrm{u}}_{\mathrm{g}}$
$\mathrm{m}_{\mathrm{v}}+\mathrm{m} \ddot{v}_{\mathrm{s}}+\mathrm{C}_{\mathrm{s}} \dot{v}_{\mathrm{s}}+\mathrm{K}_{\mathrm{s}} \mathrm{v}_{\mathrm{b}}=-\mathrm{m} \ddot{u}_{\mathrm{g}}$

This can be written in matrix form as

$\left[\begin{array}{cc}M & m \\ m & m\end{array}\right]\left\{\begin{array}{l}\ddot{o}_{b} \\ \ddot{v}_{s}\end{array}\right\}+\left[\begin{array}{cc}C_{b} & 0 \\ 0 & C_{s}\end{array}\right]\left\{\begin{array}{l}\dot{v}_{b} \\ \dot{v}_{s}\end{array}\right\}+\left[\begin{array}{cc}K_{b} & 0 \\ 0 & K_{s}\end{array}\right]\left\{\begin{array}{l}v_{b} \\ v_{s}\end{array}\right\}=\left[\begin{array}{cc}M & m \\ m & m\end{array}\right]$ $\left\{\begin{array}{c}1 \\ 0\end{array}\right\} \ddot{\mathrm{u}}_{\mathrm{g}}$

Where $M=m+m_{b}$ 
$\mathrm{M} \ddot{v}+\mathrm{C} \dot{\mathrm{v}}+\mathrm{Kv}=-\mathrm{Mrü}$

Mass ratio $\gamma$ is given by

$$
\gamma=\frac{m}{m+m_{b}}=\frac{m}{M}
$$

The natural frequencies $\omega_{\mathrm{b}}$ and $\omega_{\mathrm{s}}$ are given by

$$
\omega_{\mathrm{b}}^{2}=\frac{\mathrm{K}_{\mathrm{b}}}{\mathrm{m}+\mathrm{m}_{\mathrm{b}}} \quad \omega_{\mathrm{s}}^{2}=\frac{\mathrm{K}_{\mathrm{s}}}{\mathrm{m}}
$$

The damping factors $\beta_{\mathrm{b}}$ and $\beta_{\mathrm{s}}$ are given by

$$
2 \omega_{\mathrm{b}} \beta_{\mathrm{b}}=\frac{\mathrm{C}_{\mathrm{b}}}{\mathrm{m}+\mathrm{m}_{\mathrm{b}}} \quad 2 \omega_{\mathrm{b}} \beta_{\mathrm{b}}=\frac{\mathrm{C}_{\mathrm{s}}}{\mathrm{m}}
$$

In terms of these quantities, the basic equation of motion becomes

$$
\begin{array}{r}
\gamma \ddot{v}_{\mathrm{s}}+\ddot{\mathrm{v}}_{\mathrm{b}}+2 \omega_{\mathrm{b}} \beta_{\mathrm{b}} \dot{\mathrm{v}}_{\mathrm{b}}+\omega_{\mathrm{b}}^{2} \mathrm{v}_{\mathrm{b}}=-\ddot{\mathrm{u}}_{\mathrm{g}} \\
\ddot{\mathrm{v}}_{\mathrm{s}}+\ddot{\mathrm{v}}_{\mathrm{b}}+2 \omega_{\mathrm{s}} \beta_{\mathrm{s}} \dot{\mathrm{v}}_{\mathrm{s}}+\omega_{\mathrm{s}}^{2} \mathrm{v}_{\mathrm{s}}=-\ddot{\mathrm{u}}_{\mathrm{g}}
\end{array}
$$

$m$

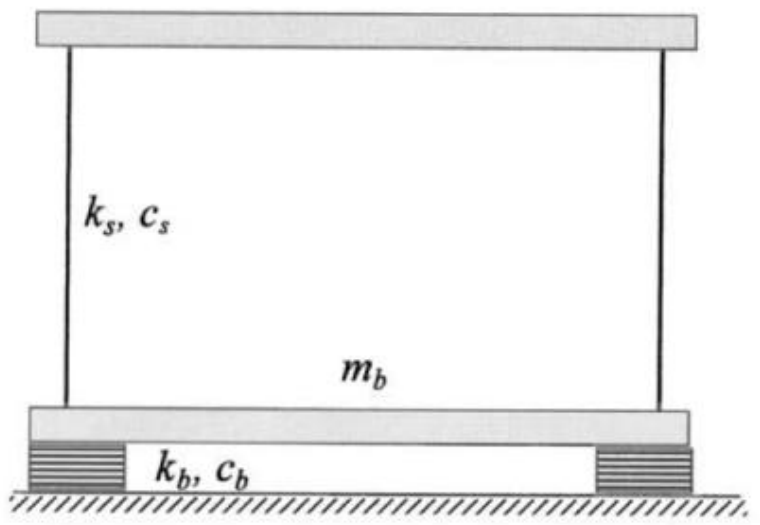

Fig -3: Parameters of two degree of freedom isolation system [1]

\section{DEVELOPMENT OF EQUATIONS}

\subsection{To Find the Thickness of Isolator}

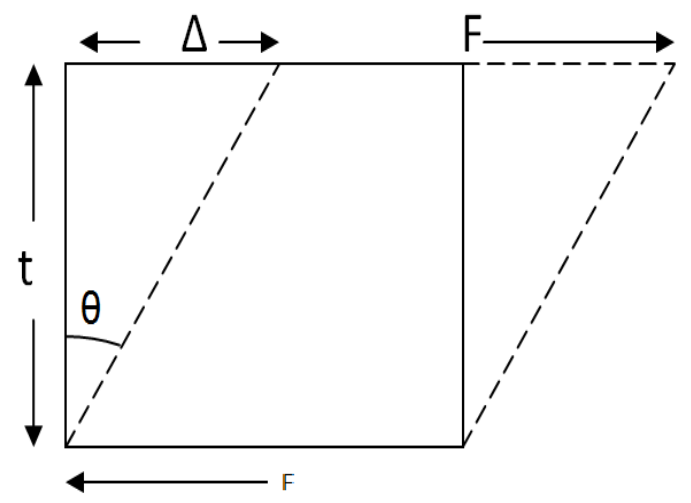

Fig -4: Behaviour of isolator under shear
Shear strain of the isolator, $\gamma$ is given by (Figure 4),

$$
\gamma=\frac{\Delta}{\mathrm{t}}
$$

Where $\Delta=$ Length of deformation $\mathrm{t}=$ thickness of the isolator

$\gamma$ is assumed to be $100 \%$ in this analysis.

Therefore, $\Delta=t$

$S_{d}$ is the spectral displacement of the structure as per IS 1893-2002 Part I. We assume that the isolator gets deformed keeping the structure intact. Hence the maximum displacement of isolator is $S_{d}$

i.e,

$$
S_{d}=t
$$

But,

$$
\mathrm{S}_{\mathrm{d}}=\frac{\mathrm{Sa}}{\omega^{2}}
$$

Therefore

$$
\mathrm{t}=\frac{S_{a}}{\omega^{2}}
$$

Where,

$\mathrm{S}_{\mathrm{a}}=$ Spectral acceleration of the isolator $\omega=$ frequency of the structure

By considering the zone factor $(\mathrm{Z})$, importance factor $(\mathrm{I})$ and response reduction factor $(\mathrm{R})$, the above equation can be written as

$$
\mathrm{t}=\frac{\mathrm{A}_{\mathrm{h}}}{\omega^{2}}
$$

Where, the horizontal acceleration coefficient,

$$
\begin{array}{ll}
\text { for DBE, } & \mathrm{A}_{\mathrm{h}}=\frac{\mathrm{Z}}{2} \frac{\mathrm{I}}{\mathrm{R}} \frac{\mathrm{S}_{\mathrm{a}}}{\mathrm{g}} \\
\text { for MCE } & \mathrm{A}_{\mathrm{h}}=\mathrm{Z} \frac{\mathrm{I}}{\mathrm{R}} \frac{\mathrm{S}_{\mathrm{a}}}{\mathrm{g}}
\end{array}
$$

\subsection{To Find Diameter of Isolator:}

The linear frequency of the isolator is given by,

$$
\mathrm{f}=\frac{1}{2 \pi} \sqrt{\frac{\mathrm{k}}{\mathrm{m}}}
$$

Where $\mathrm{k}=$ Stiffness of the isolator $\mathrm{m}=$ Mass of the isolator

$$
\begin{aligned}
2 \pi f & =\sqrt{\frac{\mathrm{k}}{\mathrm{m}}} \\
\omega^{2}=\frac{\mathrm{k}}{\mathrm{m}} & {[10] }
\end{aligned}
$$

$\omega=$ Natural frequency of the isolator 
Horizontal stiffness of the isolator,

$$
\mathrm{K}_{\mathrm{H}}=\frac{\text { Load }}{\text { Deflection }}
$$

Load $=$ Shear stress $X$ Cross sectional area

From eq (11),

$$
K_{H}=\frac{G A}{t}
$$

Substituting the value of stiffness in Eq.(10), we get

$$
\omega^{2}=\frac{\mathrm{GA}}{\mathrm{tm}}
$$

$$
\frac{\mathrm{GA}}{\omega^{2} \mathrm{t}}=\frac{\mathrm{W}}{\mathrm{g}}
$$

Using $\mathrm{Eq}(5)$ the above equation can be modified as,

$$
\frac{\mathrm{Gg}}{\omega^{2} S_{d}}=\frac{\mathrm{W}}{\mathrm{A}}
$$

Also

$$
\mathrm{S}_{\mathrm{d}}=\frac{\mathrm{S}_{\mathrm{a}}}{\omega^{2}}
$$

Substituting $\operatorname{Eq}(15)$ in $\operatorname{Eq}(14)$,

$$
\frac{G}{\left(\frac{S a}{g}\right)}=\frac{W}{A}
$$

Therefore,

$$
\begin{gathered}
\mathrm{A}=\frac{\mathrm{W}\left(\frac{\mathrm{Sa}}{\mathrm{g}}\right)}{\mathrm{G}} \\
\mathrm{D}=\sqrt{\frac{4 \mathrm{~W}\left(\frac{\mathrm{Sa}}{\mathrm{g}}\right)}{\text { лG}}}
\end{gathered}
$$

Incorporating the Importance factor, Response reduction factor and Zone factor, the above equation can be modified as

$$
\mathrm{D}=\sqrt{\frac{4 \mathrm{Wf} \alpha_{1} \alpha_{2} \alpha_{3}}{\pi \mathrm{G}}}
$$

Where

$$
\begin{array}{r}
\alpha_{2}=\left\{\begin{array}{c}
\frac{z}{R} \text { for DBE } \\
2 \text { for MCE }
\end{array}\right.
\end{array}
$$

$$
\alpha_{3}=\left\{\begin{array}{l}
1.0 \text { for hard soil } \\
1.36 \text { for medium soil } \\
1.67 \text { for soft soil }
\end{array}\right.
$$

\subsection{Layering of Isolator}

To keep the ratio of the horizontal and vertical stiffness equal for the different isolator sets, a parameter called Shape factor, $\mathrm{S}$ is introduced, which is a dimensionless measure of the aspect ratio of the single layer of the elastomer. For a single pad in the form of a complete circle, the compression modulus $\mathrm{E}_{\mathrm{C}}$ is given by

$$
E_{C} \approx 6 G S^{2}
$$

Also,

$$
K_{v}=\frac{E_{c} A}{t}
$$

Considering Eq (12) and $\mathrm{Eq}(20)$, the following relation can be obtained.

$$
\frac{E_{c}}{G}=\frac{K_{v}}{K_{H}}
$$

From $\operatorname{Eq}(10)$,

$$
\frac{E_{C}}{G}=\frac{\omega_{v}^{2}}{\omega_{H}^{2}}
$$

Or, it can be further modified as

$$
\frac{E_{C}}{G}=\frac{f_{v}^{2}}{f_{H}^{2}}
$$

Therefore $\operatorname{Eq}(19)$ can be re-written as,

$$
6 \mathrm{~S}^{2}=\frac{\mathrm{f}_{\mathrm{v}}^{2}}{\mathrm{f}_{\mathrm{H}}^{2}}
$$

It is assumed that $f_{V}=20 f_{H}$

Therefore, $S \approx 10$

$$
S=\frac{\text { Loaded area }}{\text { Force free area }}
$$

For circular isolator,

$$
\begin{aligned}
& S=\frac{\text { Cross section area }}{\text { Curved surface area }} \\
& S=\frac{\pi D^{2} / 4}{\pi D t} \\
& S=\frac{D}{4 t}
\end{aligned}
$$


Therefore,

$$
\mathrm{t}=\frac{\mathrm{D}}{4 \mathrm{~S}}
$$

The above equation shows that by varying the number of sandwich layer, quite a large variation in vertical stiffness of the individual isolator element could be achieved.

\section{DESIGN CHARTS}

After the equations were developed, a set of charts were prepared for easy designing of circular laminated rubber bearing isolator (LBR). The charts were prepared according to IS 1893 (Part 1): 2002. Charts were prepared for all the four seismic zones, namely, low (zone II), moderate (zone III), severe (zone IV) and very severe (zone V). The three types of soil sites, namely, rocky or hard soil site (Type I), medium soil site (Type II) and soft soil site (Type III) are also considered. Charts for different damping ratios like 0 , $2,5,7,10,15,20,25$, and 30 are prepared. Importance factor (I) and Response reduction factor (R) is taken as 1 for all the charts to enable the designer to choose their criteria. Diameter for circular rubber isolators having shear modulus value $0.35 \mathrm{MPa}, 0.7 \mathrm{MPa}, 1.05 \mathrm{MPa}, 1.40 \mathrm{MPa}$ is developed. Chart 1 is a typical chart to find the thickness of rubber for zone $\mathrm{V}$ and three soil conditions for Design basis earthquake for 5\% damping. Chart 2 is to find the diameter of isolator for building with desired time period 2 seconds for Design basis earthquake for zone $\mathrm{V}$ and for soft soil condition for axial load varying from $50 \mathrm{kN}$ to $10000 \mathrm{kN}$.

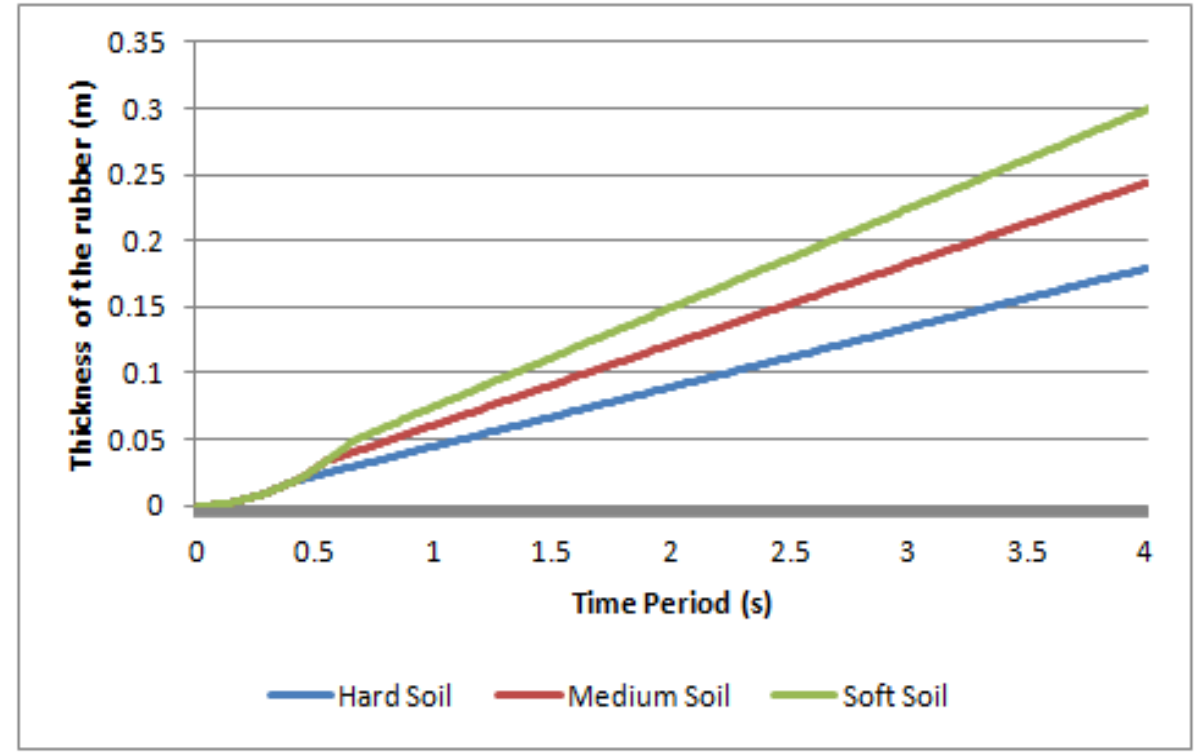

Chart - 1: Chart for DBE for 5\% damping in Zone V

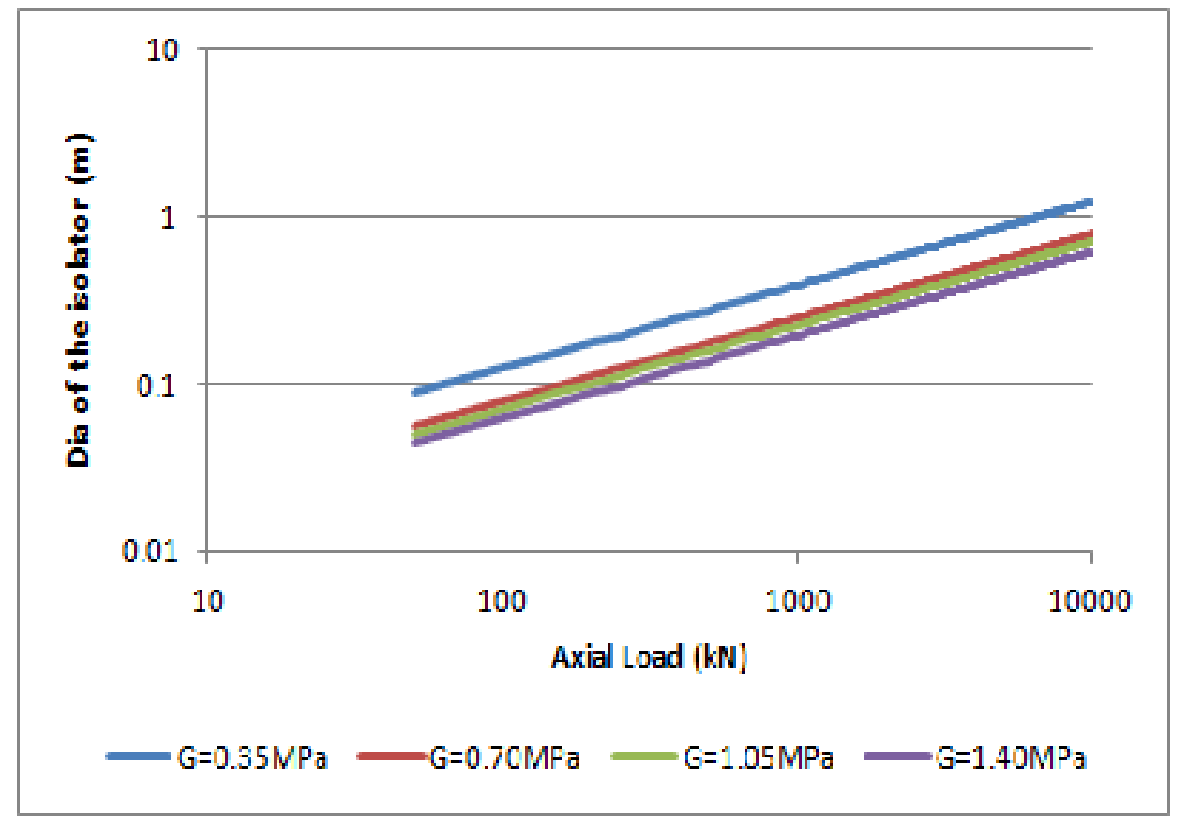

Chart -2:.Chart for DBE for $\mathrm{T}=2$ s Soft soil condition(Zone V) 


\subsection{Interpretation of Charts}

\subsubsection{To get the Thickness}

To get the thickness of the isolator, the desired time period of the structure after isolation should be assumed. Corresponding value of thickness can be obtained from the graph (Chart 1) according to the soil condition, damping and type of the earthquake considered. According to the type of structure and importance of structure, Response reduction factor (R) and Importance factor (I) can be incorporated to get the final thickness of rubber in the isolator. Further calculations can be done for obtaining the layering.

\subsubsection{To get the Diameter}

The diameter of the isolator can be obtained by knowing the axial load coming on the column and the shear modulus of the rubber used. From the corresponding charts (Chart 2) for particular design time period and soil condition, the value of diameter can be taken. Further calculations considering the Response reduction factor (R) and Importance factor (I) should be done to get the final diameter of the isolator.

\section{CASE STUDY}

\subsection{Description of the Structure Analyzed}

The structure analysed is a two bay three storied reinforced concrete framed structure consisting of three frames (Frame1 to Frame-3). The centre to centre distance between the columns is $3000 \mathrm{~mm}$ and the height of each storey is $3600 \mathrm{~mm}$. The column section is of $300 \mathrm{~mm} \mathrm{X} \mathrm{400mm} \mathrm{size}$ consisting of two $16 \mathrm{~mm}$ bars at top and bottom. The beam section is also of $300 \mathrm{~mm} \mathrm{X} 400 \mathrm{~mm}$ size consisting of two $12 \mathrm{~mm}$ bars on either side.

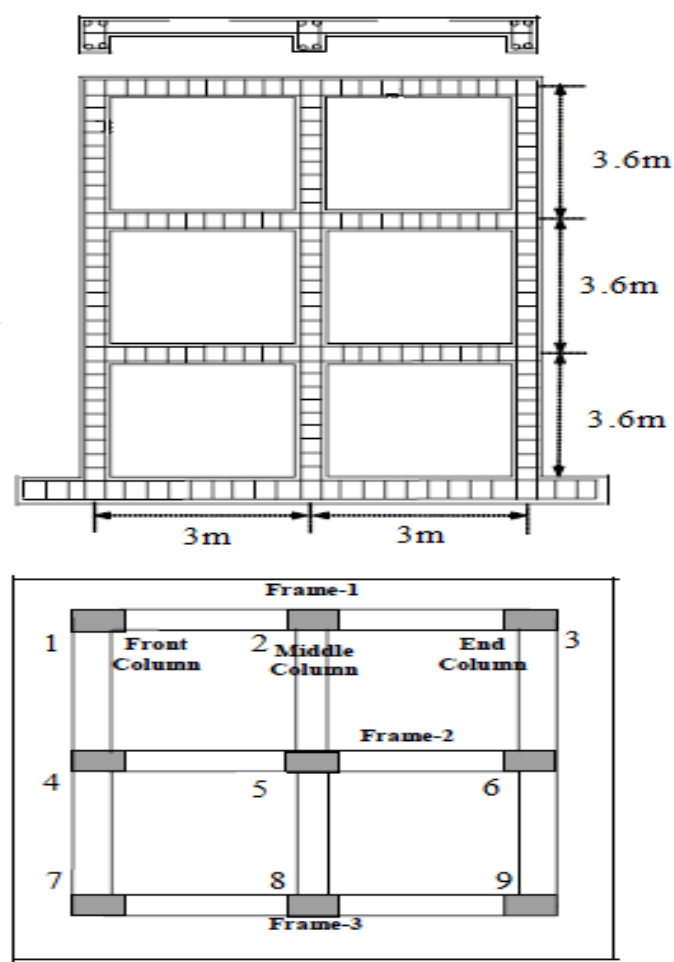

Fig -5: Elevation and plan view of the frame
Column has $8 \mathrm{~mm}$ diameter ties spaced at $150 \mathrm{~mm}$ centres and beam has $8 \mathrm{~mm}$ diameter two legged stirrups at $100 \mathrm{~mm}$ centres. The slab is $150 \mathrm{~mm}$ thick with $12 \mathrm{~mm}$ bars at $200 \mathrm{~mm}$ centres with reinforcement for support moment provided separately. Figure 5 shows the elevation and typical plan view of the frame tested for verification of time history analysis methodology.

\subsection{Design of Base Isolator}

Models were created in SAP 2000 without base isolator (Figure 6), with linear base isolator and with non-linear base isolator. Dead load analysis was done for the self weight of the system and axial load acting on each column was obtained (Table 1). The structure was assumed to be in Zone $\mathrm{V}$, built on soft soil. The rubber used for the isolator is assumed to have a shear modulus of $0.35 \mathrm{MPa}$.

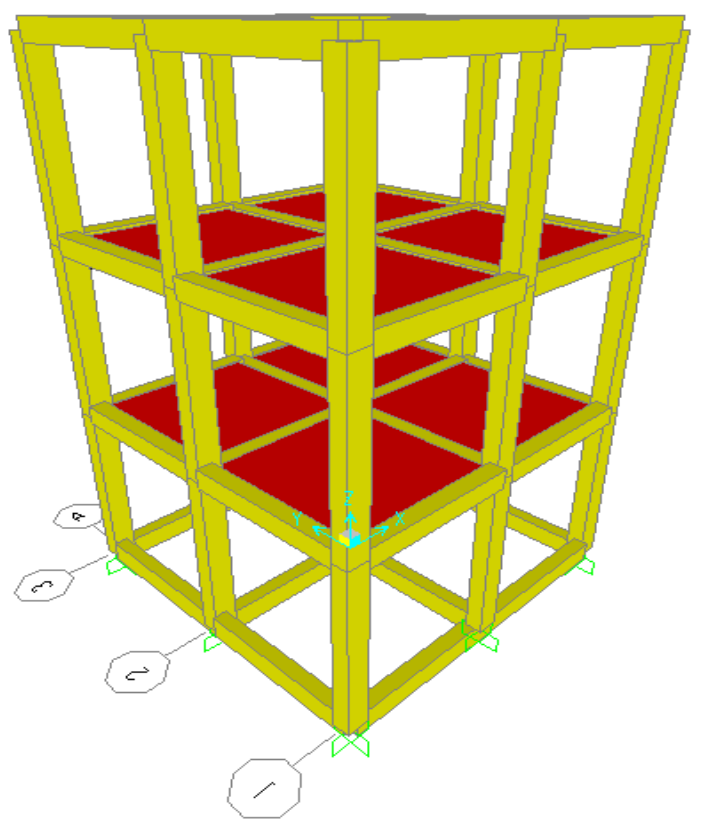

Fig -6: SAP 2000 model of the frame

Table1. Axial load on column and dimensions of base isolator

\begin{tabular}{|l|l|l|l|l|}
\hline $\begin{array}{l}\text { Column } \\
\text { Number }\end{array}$ & $\begin{array}{l}\text { Axial } \\
\text { Load } \\
(\mathbf{k N})\end{array}$ & $\begin{array}{l}\text { Thickness } \\
\text { of Rubber } \\
(\mathbf{m m})\end{array}$ & $\begin{array}{l}\text { Diameter } \\
\text { of } \\
\text { Isolator } \\
(\mathbf{m m})\end{array}$ & $\begin{array}{l}\text { Thickness } \\
\text { of Layer } \\
(\mathbf{m m})\end{array}$ \\
\hline 1 & 81.45 & 150 & 220 & 5.5 \\
\hline 2 & 122.8 & 150 & 280 & 7 \\
\hline 3 & 81.45 & 150 & 220 & 5.5 \\
\hline 4 & 127.1 & 150 & 280 & 7 \\
\hline 5 & 195.1 & 150 & 420 & 11 \\
\hline 6 & 127.1 & 150 & 280 & 7 \\
\hline 7 & 81.45 & 150 & 220 & 5.5 \\
\hline 8 & 122.8 & 150 & 280 & 7 \\
\hline 9 & 81.45 & 150 & 220 & 5.5 \\
\hline
\end{tabular}

Columns 1, 3, 7 and 9 have same axial load. Also, columns 2, 4, 6 and 8 have similar loads. Therefore, 3 isolators were designed for the whole structure. 


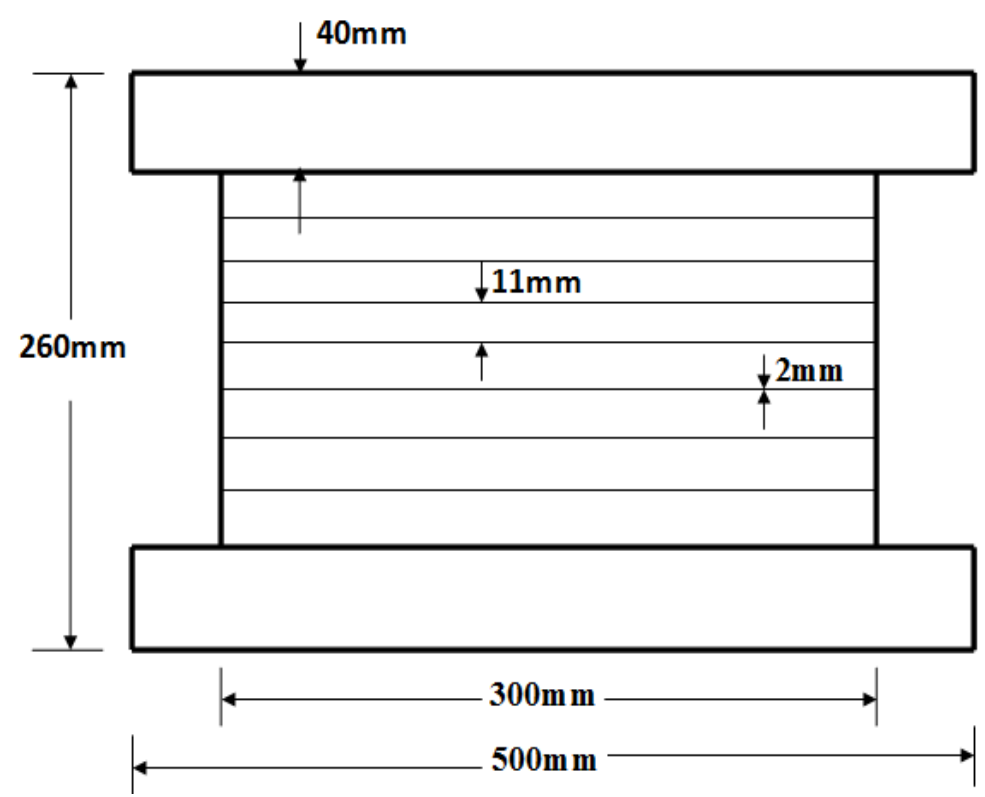

Fig -7: Detail design of isolator for central column

The detail design of isolator below the central column is given in Figure 7.

\subsection{Linear Time History Analysis}

Initially a gravity load analysis and modal analysis is carried out the system. Linear time history analysis of the frame is carried out using SAP-2000 software. El Centro earthquake (Figure 8) is used in the time history analysis. Figure 9 shows the SAP-2000 model of the frame with base isolator.

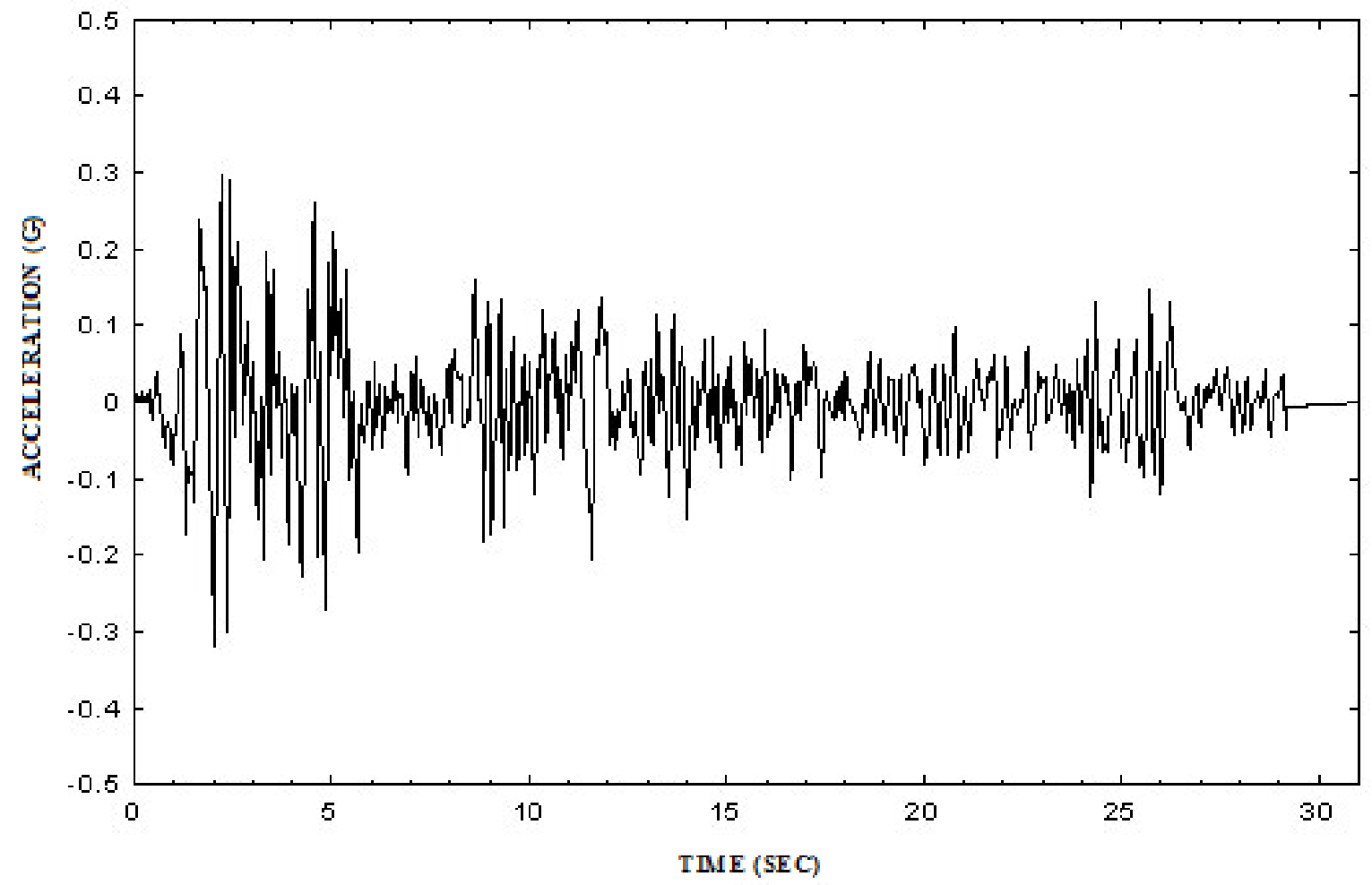

Fig -8: North-South component of El Centro earthquake, May 18, 1940 


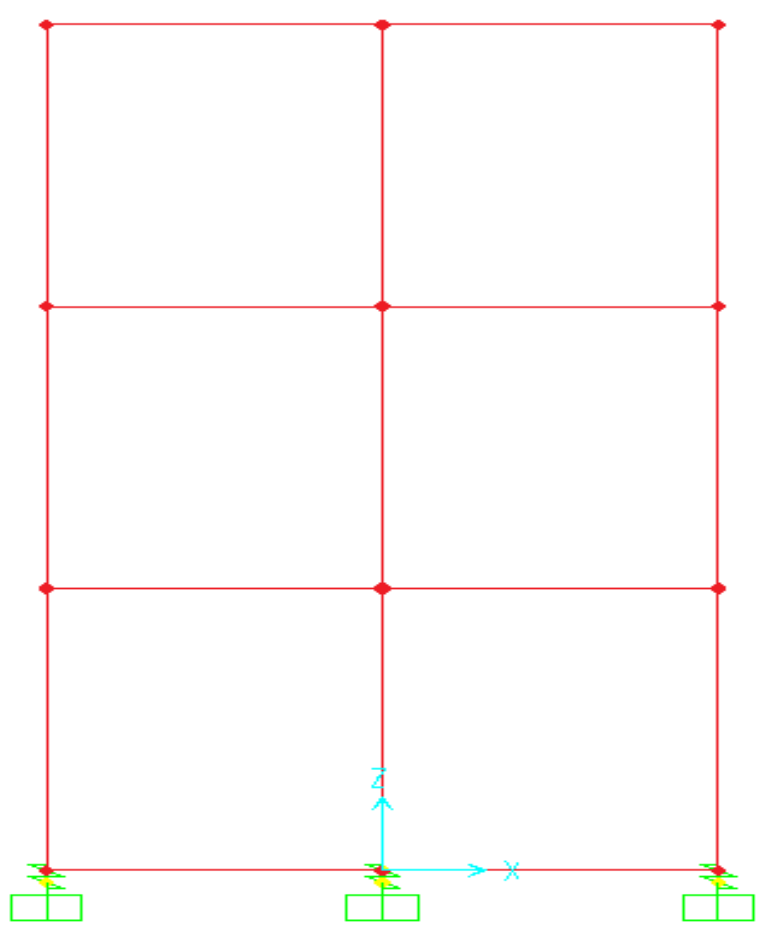

Fig -9: SAP model of the frame with base isolator

Acceleration on the building and displacement of the building, before and after installation of base isolator is compared. Graphs are plotted for the same (Chart 3 and 4).

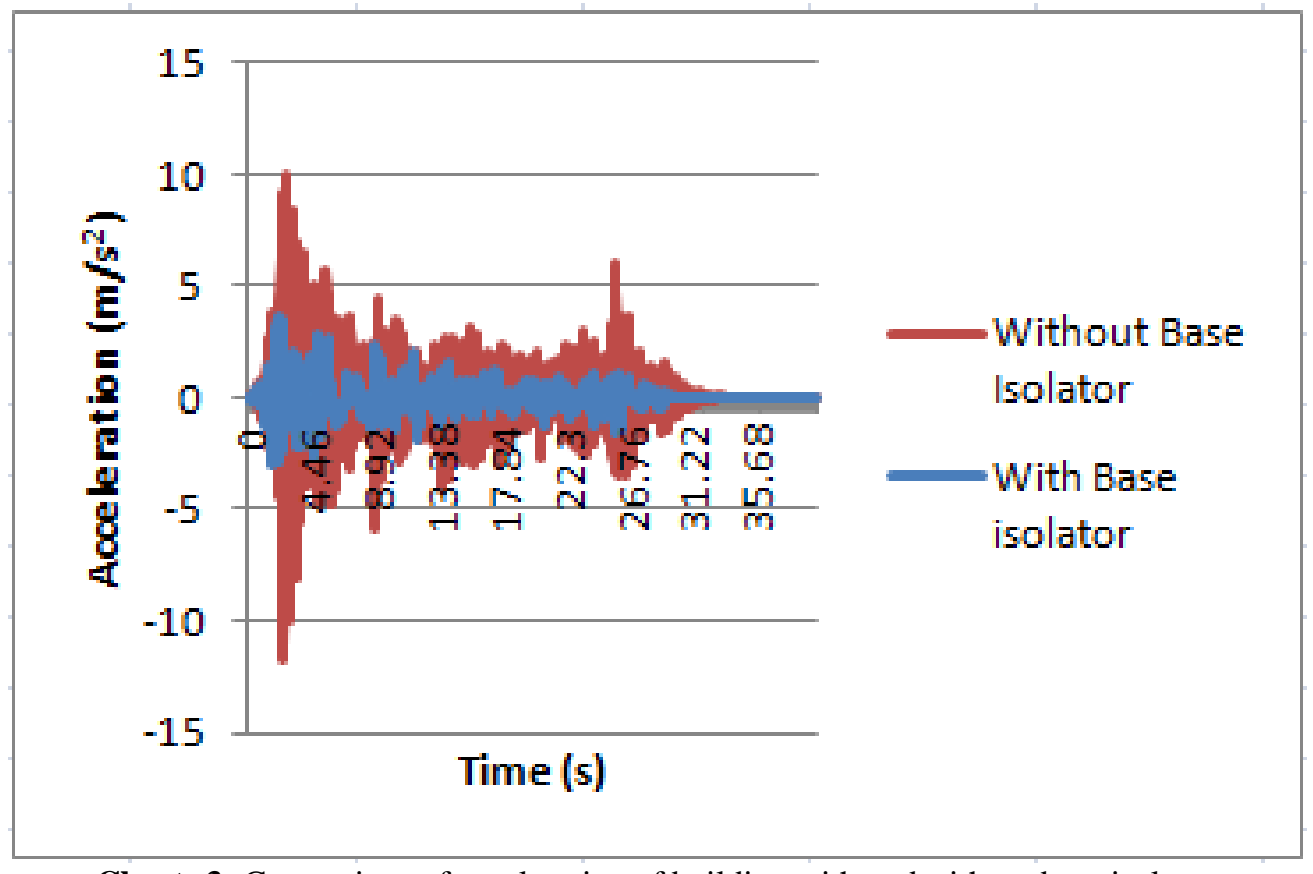

Chart -3: Comparison of acceleration of building with and without base isolator 


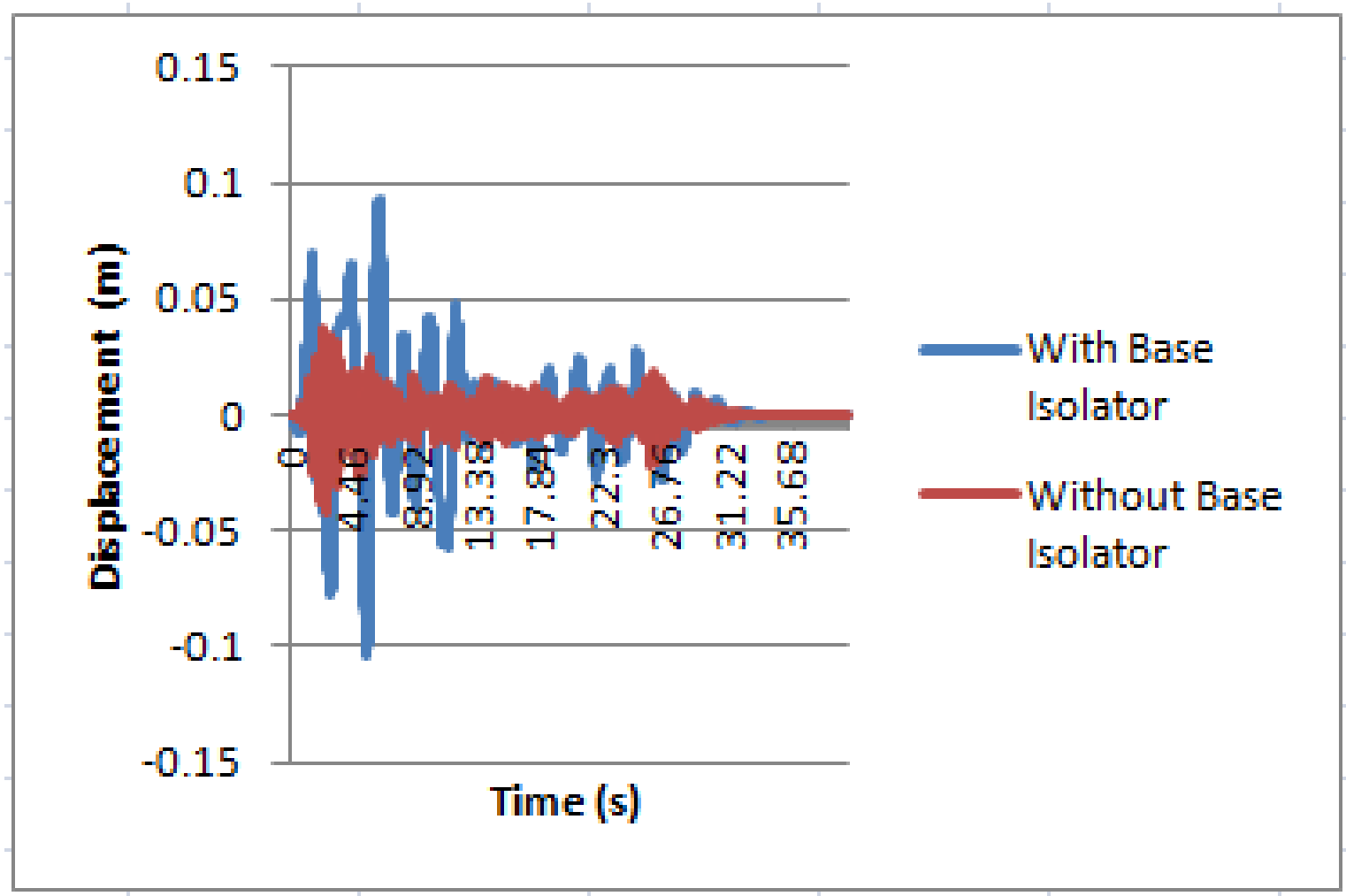

Chart -4: Comparison of displacement of building with and without base isolator.

\subsection{Non-Linear Time History Analysis}

The non-linear behavior of isolator is simplified as bilinear [3]. The post yielding stiffness ratios $(\alpha)$ are assumed to be $0.05,0.1$ and 0.15 for the isolator. The yield strength of non-linear case $\left(\mathrm{F}_{1}\right)$ is taken as one-tenth, one-fifth, one-third, half and three-fourth of yield strength of linear case $\left(\mathrm{F}_{1, \text { elastic }}\right)$. Fifteen cases are considered in total. Bilinear hysteresis loops were obtained. A typical bilinear hysteresis loop for for $\alpha=0.05$ and $F_{1}=0.1 F_{1 \text {,elastic }}$ is shown in Chart 5 .

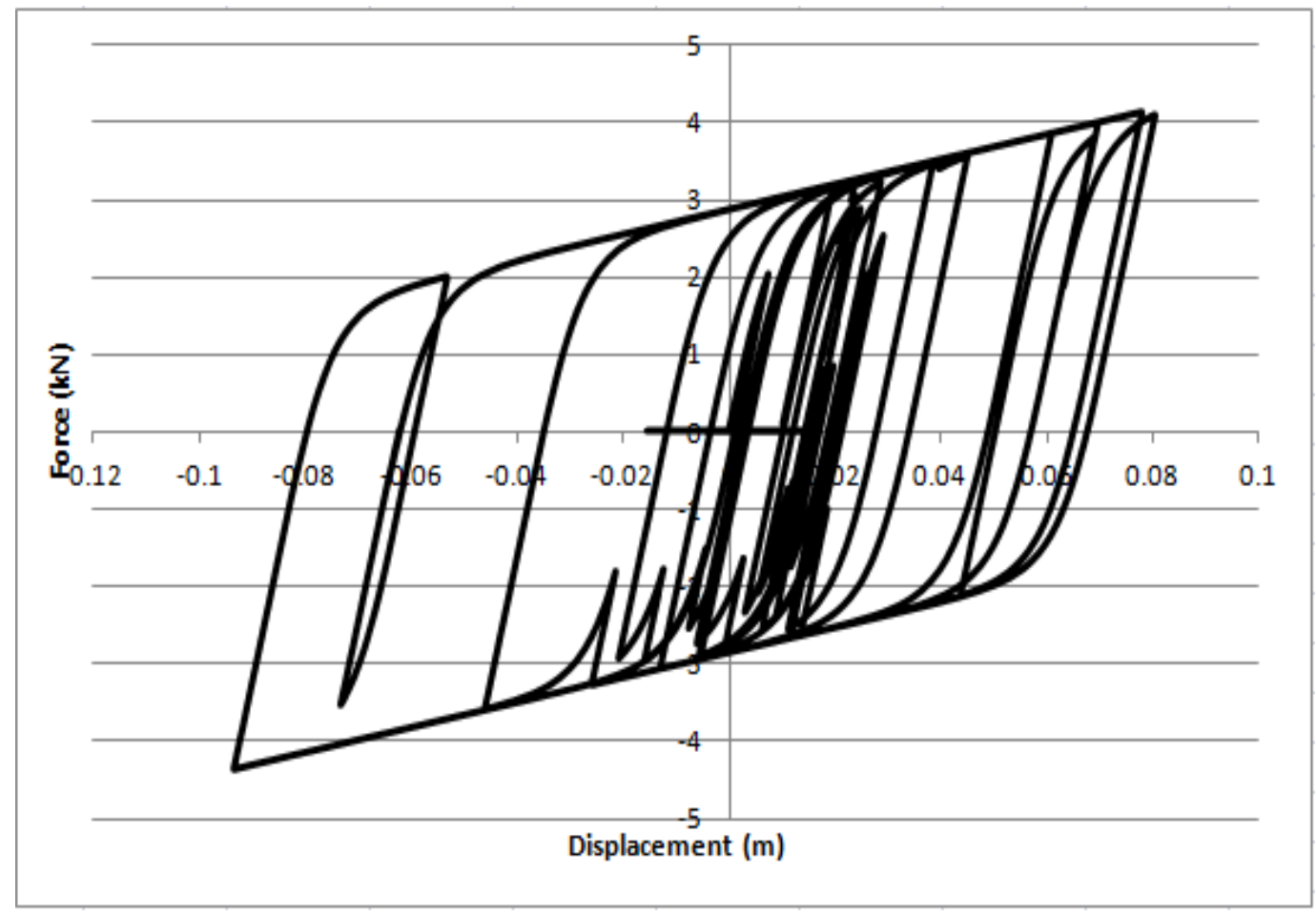

Chart -5:Bilinear hysteresis loop for $\alpha=0.05$ and $F_{1}=0.1 F_{1, \text { elastic }}$ 
From the hysteresis loop, the additional damping and the effective stiffness values are calculated. The values are given in Table 2.

Table -2: Additional damping and effective stiffness of non-linear isolator

\begin{tabular}{|l|l|l|}
\hline Cases & Additional Damping $\zeta \mathbf{~ e ~ ( \% ) ~}$ & Effective Stiffness Ke $(\mathbf{k N} / \mathbf{m})$ \\
\hline$\alpha=0.05, \mathrm{~F}_{1}=0.10 \mathrm{~F}_{1, \text { elastic }}$ & 22.12 & 25.5 \\
\hline$\alpha=0.10, \mathrm{~F}_{1}=0.10 \mathrm{~F}_{1, \text { elastic }}$ & 17.53 & 38.9 \\
\hline$\alpha=0.15, \mathrm{~F}_{1}=0.10 \mathrm{~F}_{1, \text { elastic }}$ & 11.86 & 53.1 \\
\hline$\alpha=0.05, \mathrm{~F}_{1}=0.20 \mathrm{~F}_{1, \text { elastic }}$ & 25.04 & 23.3 \\
\hline$\alpha=0.10, \mathrm{~F}_{1}=0.20 \mathrm{~F}_{1, \text { elastic }}$ & 15.85 & 36.4 \\
\hline$\alpha=0.15, \mathrm{~F}_{1}=0.20 \mathrm{~F}_{1, \text { elastic }}$ & 17.19 & 52.2 \\
\hline$\alpha=0.05, \mathrm{~F}_{1}=0.33 \mathrm{~F}_{1, \text { elastic }}$ & 19.48 & 20.5 \\
\hline$\alpha=0.10, \mathrm{~F}_{1}=0.33 \mathrm{~F}_{1, \text { elastic }}$ & 15.91 & 35.5 \\
\hline$\alpha=0.15, \mathrm{~F}_{1}=0.33 \mathrm{~F}_{1, \text { elastic }}$ & 13.97 & 51.1 \\
\hline$\alpha=0.05, \mathrm{~F}_{1}=0.50 \mathrm{~F}_{1, \text { elastic }}$ & 12.98 & 18.7 \\
\hline$\alpha=0.10, \mathrm{~F}_{1}=0.50 \mathrm{~F}_{1, \text { lastic }}$ & 9.83 & 34.4 \\
\hline$\alpha=0.15, \mathrm{~F}_{1}=0.50 \mathrm{~F}_{1, \text { elastic }}$ & 8.01 & 50.3 \\
\hline$\alpha=0.05, \mathrm{~F}_{1}=0.75 \mathrm{~F}_{1, \text { elastic }}$ & 6.60 & 17.8 \\
\hline$\alpha=0.10, \mathrm{~F}_{1}=0.75 \mathrm{~F}_{1, \text { elastic }}$ & 5.67 & 33.8 \\
\hline$\alpha=0.15, \mathrm{~F}_{1}=0.75 \mathrm{~F}_{1, \text { lastic }}$ & 5.82 & 49.9 \\
\hline
\end{tabular}

\subsection{Comparison of Linear and Non-Linear Analysis}

Displacement of building with linear and non-linear base isolators is compared. Displacement is seemed to be reduced when isolators are designed as non-linear. The comparison is given in table 3 .

Table -3: Displacement reduction in non-linear analysis

\begin{tabular}{|l|l|l|}
\hline Cases & Displacement (m) & Reduction (\%) \\
\hline$\alpha=0.05, \mathrm{~F}_{1}=0.10 \mathrm{~F}_{1, \text { elastic }}$ & 0.0789 & 32.61 \\
\hline$\alpha=0.10, \mathrm{~F}_{1}=0.10 \mathrm{~F}_{1, \text { elastic }}$ & 0.0853 & 27.13 \\
\hline$\alpha=0.15, \mathrm{~F}_{1}=0.10 \mathrm{~F}_{1, \text { elastic }}$ & 0.0947 & 19.10 \\
\hline$\alpha=0.05, \mathrm{~F}_{1}=0.20 \mathrm{~F}_{1, \text { elastic }}$ & 0.0885 & 24.40 \\
\hline$\alpha=0.10, \mathrm{~F}_{1}=0.20 \mathrm{~F}_{1, \text { elastic }}$ & 0.0783 & 33.09 \\
\hline$\alpha=0.15, \mathrm{~F}_{1}=0.20 \mathrm{~F}_{1, \text { elastic }}$ & 0.0806 & 31.12 \\
\hline$\alpha=0.05, \mathrm{~F}_{1}=0.33 \mathrm{~F}_{1, \text { elastic }}$ & 0.0915 & 21.84 \\
\hline$\alpha=0.10, \mathrm{~F}_{1}=0.33 \mathrm{~F}_{1, \text { elastic }}$ & 0.0852 & 27.15 \\
\hline$\alpha=0.15, \mathrm{~F}_{1}=0.33 \mathrm{~F}_{1, \text { elastic }}$ & 0.0850 & 27.33 \\
\hline$\alpha=0.05, \mathrm{~F}_{1}=0.50 \mathrm{~F}_{1, \text { elastic }}$ & 0.0927 & 20.81 \\
\hline$\alpha=0.10, \mathrm{~F}_{1}=0.50 \mathrm{~F}_{1, \text { elastic }}$ & 0.0930 & 20.52 \\
\hline$\alpha=0.15, \mathrm{~F}_{1}=0.50 \mathrm{~F}_{1, \text { elastic }}$ & 0.0926 & 20.86 \\
\hline$\alpha=0.05, \mathrm{~F}_{1}=0.75 \mathrm{~F}_{1, \text { elastic }}$ & 0.0963 & 17.70 \\
\hline$\alpha=0.10, \mathrm{~F}_{1}=0.75 \mathrm{~F}_{1, \text { elastic }}$ & 0.0954 & 18.44 \\
\hline$\alpha=0.15, \mathrm{~F}_{1}=0.75 \mathrm{~F}_{1, \text { elastic }}$ & 0.0946 & 19.11 \\
\hline
\end{tabular}

\section{RESULTS}

- $\quad$ For the same soil condition and time period, thickness of the isolator decreases with increase in damping percentage.

- Buildings situated on soft soil conditions require thicker isolator than those situated on hard soil conditions, provided the required time period and damping are the same.

- For a particular value of axial load which is to be transferred, the diameter of the isolator increases, as isolator with rubber of lesser value of shear modulus is used.

- The diameter of isolator decreases as the desired value of time period increases, provided the soil condition and the rubber used are the same.

- Buildings situated on soft soils need isolator with bigger diameter than situated on hard rocky soils.

- Both thickness and diameter increases as greater earthquake prone area is chosen. 
Linear time history analysis shows that acceleration on the building decreases after the installation of base isolator, whereas the building displacement increases after the installation. The maximum value of acceleration on the building before the introduction of base isolator is $10.96 \mathrm{~m} / \mathrm{s}^{2}$ and after the installation is $1.12 \mathrm{~m} / \mathrm{s}^{2}$. The value of building displacement is $40.68 \mathrm{~mm}$ before installing isolator and $117.7 \mathrm{~mm}$ after the installation.

Results of non-linear analysis shows that a maximum additional damping of $25.04 \%$ was obtained for post yielding stiffness ratio of 0.05 and non-linear yield strength taken as one-fifth of linear yield strength.

On comparing linear and non-linear isolators, a maximum displacement reduction of $33.09 \%$ in the case of post yielding stiffness ratio of 0.10 and non-linear yield strength taken as one-fifth of linear yield strength was obtained, when the isolators are designed as non-linear.

\section{CONCLUSION}

The guidelines for designing laminated rubber bearing (LRB) isolators are developed. Design charts for arriving at the details of base isolators are prepared. Different isolator parameters were compared with respect to fundamental period and damping of the fixed base structure, axial load on the column, seismic zone, type of soil and shore hardness of rubber.

Acceleration on building and displacement are altered by the installation of isolator. Acceleration on the building decreases and displacement of the building increases. This increase in displacement can be reduced if the isolator is designed as non-linear. Additional damping is also introduced by the non-linear isolator.

\section{ACKNOWLEDGEMENTS}

The paper is published with the kind permission of Director, CSIR-SERC, Chennai, Tamil Nadu, India.

\section{REFERENCES}

[1]. Farzad Naeim and James. M. Kelly, Design of seismic isolated structures: From Theory to practice, John Wiley \& Sons, 1999

[2]. Anil. K. Chopra, Dynamics of structures: Theory and practice to Earthquake engineering, Prentice Hall, 1995

[3]. Andriono, T and Carr, A. J (1991), "A simplified earthquake resistant design method for base isolated multi storied structures", Bulletin of the New Zealand National Society for Earthquake Engineering. Vol 24, No 3 pp238250

[4]. Indian Standard Criteria for earthquake resistant design of structures Part 1: General provisions and buildings (Fifth revision), IS 1893:Part1(2002)

\section{BIOGRAPHIES}

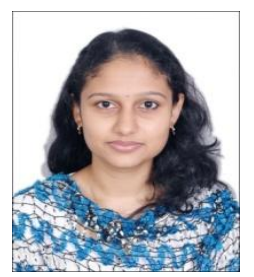

Ganga Warrier A is a Civil Engineering graduate from LBS College of Engineering, Kasaragod and is currently pursuing her Masters in Structural Engineering at Manipal Institute of Technology, Manipal. She is doing her project in CSIR-SERC, Chennai. Her research areas include seismic response control and seismic base isolation.

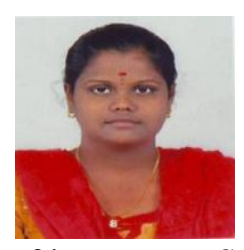

K. Balamonica is a Research Scholar in the Academy of Scientific and Innovative Research (AcSIR) and currently Senior Project Fellow in the Advanced Seismic Testing and Research Laboratory of CSIR-SERC, Chennai. Her research areas of interest are Structural dynamics, Earthquake Engineering and Structural Health Monitoring

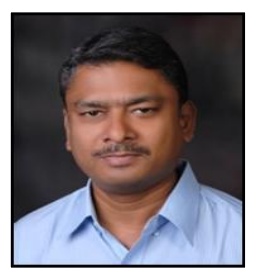

Dr. K. Sathish Kumar is currently Senior Principal Scientist in the Advanced Seismic Testing and Research Laboratory of CSIR-SERC, Chennai. He is also a Professor in the Academy of Scientific and Innovative Research (AcSIR). His research areas of interest include Seismic Response Control and Pseudo-dynamics.

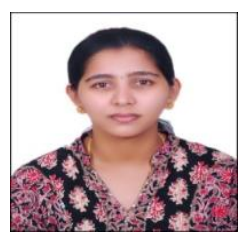

Dhanalakshmi is an Assistant Professor in Manipal Institute of Technology (MIT), Manipal. She earned Masters from MIT, Manipal and B.E degree from Dr. Ambedkar Institute of Technology, Bangalore. Her fields of interest are structural engineering and concrete technology. 